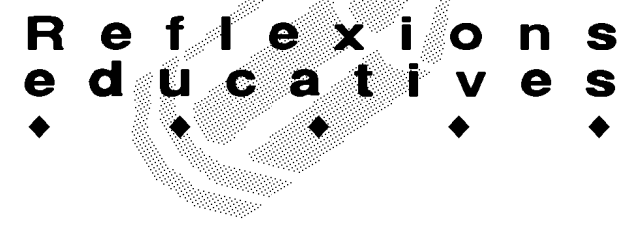

\title{
REFLEXIONS AL VOLTANT DEL PRÀCTICUM D'EDUCACIÓ INFANTIL: UN MODEL PER ESDEVENIR MESTRES?
}

\author{
Jèssica Francino Fusalba, Laura Rubio Compte i Carmina Torres Sanz. \\ Alumnes de 3r curs de Magisteri de l'ensenyament d'Educació infantil
}

\section{L'estructuració del Pràcticum II}

El Pràcticum II suposa, per a la majoria de nosaltres, alumnes de $3 r$ curs deMagisteri, el primer contacte amb el món educatiu d'una manera àmplia, després del breu i sovint quasi efímer Pràcticum I del curs anterior. És per aquest motiu que cal tenir en compte les expectatives, illusions, pors, angoixes, utopies... que cadascun de nosaltres té, de ben segur, a l'inici de les pràctiques. Però res de tot això seria possible sense uns centres educatius que ens acollissin i obrissin les portes amablement, amb ganes d'ajudar-nos a formar part de la seva quotidianitat, almenys durant uns mesos, per conèixer així el context real en el qual es desenvolupa l'activitat professional.

Aquesta assignatura troncal es realitza durant el primer quadrimestre del tercer curs de l'ensenyament de Mestre en les diferents especialitats i consta d'un total de 28,5 crèdits. És, per tant, l'assignatura amb més crèdits d'aquest ensenyament, i és la que ens permet posar en pràctica els coneixements adquirits durant els cursos anteriors en les diferents matèries a les aules de la facultat. Es tracta, doncs, d'unir experiència i reflexió, aprenentatge teòric i pràctic, sabers acadèmics i aprenentatges per experiència.

La facultat ens assigna un tutor/a, i el centre educatiu en el qual realitzem les pràctiques, un altre. És aquesta doble tutorització la que ens permet realitzar un treball més extens, creatiu i enriquidor, perquè són dos professionals els que ens guien, orienten, ajuden i avaluen la nostra tasca diària als centres educatius. Una tasca que ens permet comprendre la complexitat de les situacions educatives i la necessitat d'un aprenentatge continu per poder-les afrontar, que requereix unes capacitats de treball en equip i de coordinació amb altres professionals, així com la necessitat de saber resoldre conflictes de manera lògica i eficient, per tal de comprendre el que significa ser un bon professional de l'educació, amb la càrrega ètica d'autoexigència i de responsabilitat que implica treballar en el món educatiu en el qual ens mourem.

\section{Les tutories a la facultat}

Cada centre educatiu, o fins i tot cada aula, és un món. Per tant, estar tres mesos en una aula concreta d'un centre determinat suposa veure només una realitat concreta i pensar que aquesta és l'única.

Amb la tutoria a la facultat, el fet de crear un diàleg entre els companys sobre la nostra experiència a l'escola ens ha permès veure que hi ha diferents propostes educatives, diferents de la que hem viscut individualment. Aquest aspecte ha resultat positiu per a tots, especialment per als alumnes que estaven sols en un dels centres de pràctiques i que no tenien la possibilitat de compartir o contrastar la seva experiència amb ningú.

El paper del professor-tutor de la facultat, en les sessions de tutoria mantingudes durant aquests tres mesos de pràcticum, ha estat provocar l'inici al diàleg a partir de diferents preguntes plantejades, ajudar-nos en la nostra reflexió i aportar-nos el seu punt de vista personal i la seva pròpia experiència. Cada sessió començava a partir d'una pregunta concreta plantejada pel tutor, que cada alumne contestava breument. Tot seguit s'iniciava el diàleg, ampliant les pròpies aportacions i opinant o valorant les dels companys. Aquesta ha estat segurament l'activitat més enriquidora per a tots, aquella que ens ha permès veure més enllà del centre on estàvem fent pràctiques, la que ens ha obert els ulls a noves realitats, a altres maneres de fer, d'organitzar-se, de veure i de viure l'educació.

El nostre tutor, a més, va plantejar a la primera tutoria un treball complementari. La tasca consistia a buscar i llegir articles en revistes educatives sobre temes que demanessin una ampliació reflexiva de la feina que es feia al dia a dia de la classe amb nenes i nens, en qüestions que o bé no vèiem prou clar o bé requerien una ampliació. Els temes, per tant, eren lliures i podíem escollir els articles en funció dels nostres interessos, necessitats o motivacions. Això ens podia servir per a resoldre dubtes, per a adquirir informació i coneixements sobre temes del nostre interès i per a familiaritzar-nos 


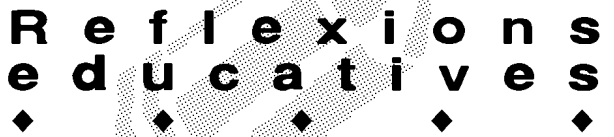

amb revistes de caire educatiu i amb les quals no estem acostumats a treballar. Amb aquestes lectures reflexives es pretenia un treball individual per després poder-lo posar en comú amb la resta de companys. En la pràctica, les sessions de pràcticum es van centrar més en els aspectes vivencials de les pràctiques, deixant de banda aquest treball plantejat amb els articles. Considerem que hauria estat un treball profitós i útil per a tots incidir en aquestes lectures, qüestió que sí que havíem treballat de manera individual.

A part d'aquesta última tasca, hem redactat individualment un diari de pràctiques on es reflecteix tot el que es feia a l'aula i el motiu pel qual es duia a terme. Aquesta tasca requeria un contacte directe amb el tutor/a del centre de pràcticum des del primer moment, ja que ens obligava a preguntar i anotar els perquès de tots els objectius i continguts treballats a l'aula. En un principi fèiem anotacions de manera més detallada, però a poc a poc, conforme estàvem immersos en la dinàmica de l'aula, ens interessà més la reflexió que l'anotació. En aquest context, a mesura que passaven els dies, nosaltres ja podíem deduir les respostes a molts perquès, donada l'estructura repetitiva característica de l'etapa d'educació infantil.

Un altre aspecte que també hem inclòs en el diari ha estat el rerefons més subjectiu de la nostra vivència personal. Un espai on hem pogut incloure reflexions o preguntes que et formules com a futur docent, com a estudiant 0 , senzillament, com a persona amb uns interessos per l'educació i pel que comporta el món educatiu en general.

La realització d'aquest diari, alhora, ha comportat poder establir una autoavaluació per ajudar-nos a conèixer en una situació real de pràctica professional, explicar les dificultats i les capacitats d'un mateix, així com els punts en els quals hauria de millorar.

\section{La unitat didàctica}

El treball de més contingut en aquest pràcticum ha estat l'elaboració i la posada en pràctica real posterior d'una unitat de programació, generalment escollida pel tutor/a del centre docent. Aquesta elecció a mans del professional sovint ha vingut donada pel fet que d'aquesta manera no s'interromp el ritme de treball habitual de l'aula, i per tant permet establir una continuïtat amb els continguts que s'imparteixen, adaptant-nos a la temporització que segueix el grup.

La planificació de qualsevol unitat de programació ens remet inevitablement al currículum d'educació infantil, partint, un cop escollit el tema que treballarem, de l'objectiu general que pretenem aconseguir: aquell que volem que els infants assoleixin un cop treballada la unitat de programació.

L'etapa d'educació infantil es caracteritza per la glo-

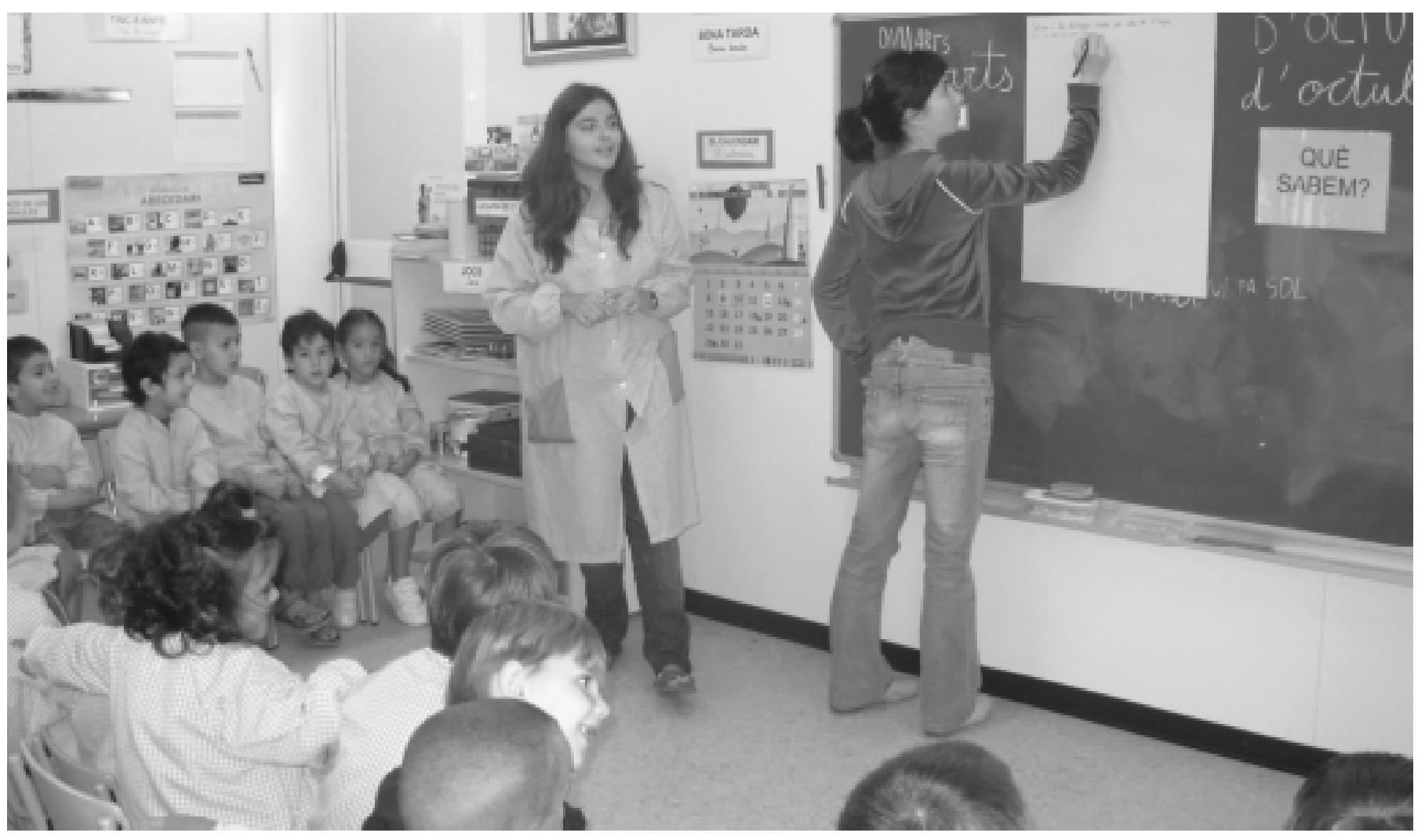




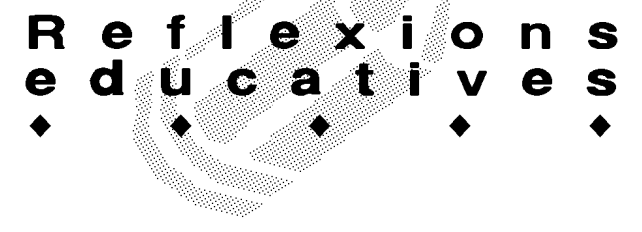

balitat dels aprenentatges, un aspecte positiu per la integració de continguts però que ha dificultat la tasca d'escollir i redactar els continguts que volem treballar de manera concreta. Això ens ha obligat a destriar els continguts que crèiem prioritaris, donant per suposat que també se'n treballarien d'altres, encara que no els hem especificat.

Un primer esquema de treball ens va ajudar a tenir una idea del que havíem de treballar, en funció de l'aula i de la programació que tenia la mestra. Aquest esquema va ser revisat en múltiples ocasions pel tutor o tutora del centre, el de la facultat i, sobretot, per un mateix. Després de diverses modificacions, correccions i adaptacions, encara va ser valorat des d'un nou punt de vista: el d'un company/a de classe, un punt sens dubte innovador, diferent i molt enriquidor en la majoria dels casos.

Aquesta darrera valoració suposava una situació d'igualtat entre l'avaluat i l'avaluador, diferent de l'habitual relació asimètrica que s'estableix entre professor i alumne. Les aportacions dels companys, generalment, es van centrar en aspectes molt concrets de la posada en pràctica i de la redacció de la unitat. En alguns casos, aquesta nova apreciació ens va servir per a modificar diferents aspectes de la temporització, la metodologia de treball, la forma d'avaluar, el tipus de redacció... En darrer terme, però, va ser el mateix alumne qui decidia modificar o no la seva programació en funció dels comentaris formulats pels companys, redactats per escrit $\mathrm{i}$ degudament justificats.

La tasca de planificar i portar a terme una unitat de programació segurament no ens venia de nou a cap dels alumnes, ja que és un treball que hem desenvolupat en diverses ocasions al llarg dels estudis de Mestre. En alguns casos, havíem posat en pràctica una part d'aquestes programacions en el context de la facultat. Ara bé, el fet de plantejar-nos que, per primera vegada, aquesta programació hauria de ser portada a la pràctica íntegrament per nosaltres mateixos dins d'un centre escolar i avaluada per diversos professionals, ho canviava tot.

En major o menor mesura, tots els companys hem estat animats i ajudats pels nostres tutors, que ens han fet les consideracions que han cregut convenients per millorar el nostre treball diari. Però, en darrer terme, ens hem trobat amb allò més temut i, alhora, més engrescador per a la majoria de nosaltres: la posada en pràctica de la unitat de programació. Una posada en pràctica que, en definitiva, depenia d'un mateix. Bé, d'un mateix i, és clar, de tots els elements contextuals, que ara no entrarem a descriure, com les expectatives pròpies i la dels altres que també ho avaluarien, el grup classe, les característiques ambientals -tan variables i imprevisibles!-, l'organització del temps i de l'espai, la disponibilitat de recursos, i un llarg etcètera.
Va ser en aquest moment quan vam poder posar en pràctica el nostre treball a partir del bagatge adquirit a la facultat. I sovint ens vam adonar de les dificultats que comporta preparar una programació amb tots els ets i uts i, sens dubte, de les mancances que tenim en l'àmbit personal i formatiu. Mancances que ens afectaren en diversos moments, com a l'hora de programar activitats adequades al ritme i al nivell d'aprenentatge, en el moment de comunicar-nos amb els infants, de contenir l'aula, de captar l'atenció, d'avaluar els continguts que s'havien treballat... Tanmateix, el fet de desenvolupar una unitat amb diverses sessions ens va permetre autoavaluar diàriament tant la programació com la nostra actuació, i d'aquesta manera modificar el que crèiem convenient. En una valoració final de la unitat de programació hem pogut recollir aquesta autoavaluació quotidiana, juntament amb altres aspectes relacionats amb el desenvolupament de la unitat, que detallem tot seguit.

Pel que fa als objectius i continguts que cadascú ha treballat, en general s'ha valorat l'adequació al nivell del grup i a les seves motivacions i interessos, i en la majoria de comentaris podem veure que la planificació era adequada. En la posada en pràctica de les activitats s'han recollit aspectes molt diversos, com la planificació del temps destinat a cada activitat, tal com expliquen alguns companys: "Volia donar per finalitzada l'activitat però, de sobte, tots els nens i nenes volien sortir a ensenyar les seves produccions [...]. En conseqüència, l'activitat es va allargar uns 10 o 15 minuts més del que estava previst, però s'havia d'aprofitar l'interès dels nens". Altrament, també s'han suprimit activitats o parts de la unitat que havíem planificat prèviament però que s'ha vist que no eren necessàries 0 , en cas contrari, se n'han introduït de noves per reforçar aspectes treballats prèviament però que no s'havien assolit. Ho podem veure recollit en el comentari següent d'una companya: "He introduït dos jocs que no estaven plantejats inicialment en la programació [...]. Tot això ho he fet perquè el primer dia em vaig adonar que seria possible que els costés assimilar el contingut que jo volia treballar i que, per tant, necessitarien més reforç del que, inicialment, havia previst".

Pel que fa a la metodologia utilitzada a l'aula, cadascú de nosaltres ha comentat diversos punts, entre els quals destaquem: aspectes comunicatius, organització o disposició dels infants dins l'aula i utilització de diferents recursos. Els comentaris següents ho exemplifiquen:

- "M'he adonat que he tingut dificultats a l'hora de controlar el meu to de veu, l'entonació... per adaptarlo a cada moment concret".

- "En aquesta activitat va funcionar el fet d'asseure'ns al terra, en rotllana, perquè jo podia veure tots els nens i, alhora, ells podien veure més bé les coses que jo els mostrava". 


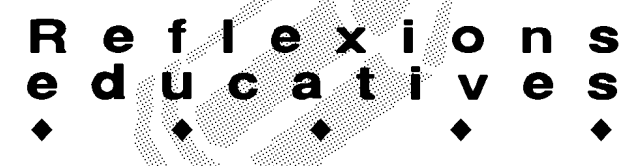

- "He vist que és molt important que els infants puguin manipular, observar i experimentar amb el material perquè puguin vivenciar-lo $\mathrm{i}$, més endavant, poder treballar de manera més abstracta".

Aquesta avaluació de la unitat que hem fet, i que ha quedat plasmada en la memòria de Pràcticum II, ens ha servit per a reflexionar de manera més objectiva sobre aspectes, tant globals com concrets, del desenvolupament de la unitat i per a prendre consciència dels punts forts i febles de la programació i de la nostra manera de dur-la a terme. Creiem que reflecteix la realitat del que volia ser i del que realment va esdevenir.

\section{Valoració del Pràcticum}

Durant la realització del Pràcticum hem pogut apreciar els nostres coneixements i habilitats, però també les nostres mancances. Ho sintetitzarem:

Hem comprovat la necessitat que té un mestre de dominar infinitat de recursos, registres, continguts, metodologies de treball..., cosa que fa imprescindible una formació continuada en tots aquests àmbits, un cop finalitzats els estudis i durant la carrera. Som conscients que la facultat ens proporciona una formació general i bàsica per entrar dins el món de l'educació, i a partir d'aquí hem de ser nosaltres els responsables d'ampliar-la, amb l'oferta formativa complementària que tenim a l'abast.

El Pràcticum a l'etapa d'educació infantil s'ha caracteritzat per una gran diversitat de centres, i dins de cada

centre, per una manera diferent de fer segons l'edat dels infants, la forma de coordinar-se, l'estatus dels pares, la participació activa o no tant dels pares, la forma cooperativa de treballar, etc. Amb l'estructura actual del Pràcticum II de Magisteri, ens ha estat possible conèixer a fons una d'aquestes realitats en concret, però sovint no ens ha permès conèixer la gran varietat existent. Això fa que pensem que d'aquí a uns mesos, quan la majoria de nosaltres estarem immersos dins el món laboral, en molts casos no estarem suficientment preparats per dur a terme la nostra tasca educativa en determinats centres i nivells. Matisem-ho: creiem que seria interessant poder accedir a diferents realitats educatives i no a una de sola (escoles rurals, centres públics, privats o concertats, ZER, llars d'infants, classes amb majoria de nouvinguts, aules amb un gruix de multiculturalisme que sobrepassa allò que podríem entendre com a normal si és que aquest terme existeix, etc.) en el període del Pràcticum II, per fernos més conscients de les múltiples realitats. Entenem la dificultat d'encaixar alumnes de facultat amb escoles d'educació infantil, però creiem que s'hauria d'intentar. Pensem, finalment, que l'assignatura del Pràcticum II, a més de ser la que té més crèdits dins la carrera de Magisteri, segurament és una de les que té més repercussió en l'àmbit personal i formatiu, tant pel que fa al nostre aprenentatge present com futur. La nostra experiència ha resultat molt gratificant; per això volem agrair la dedicació i disponibilitat de les escoles i de tots els que l'han fet possible.

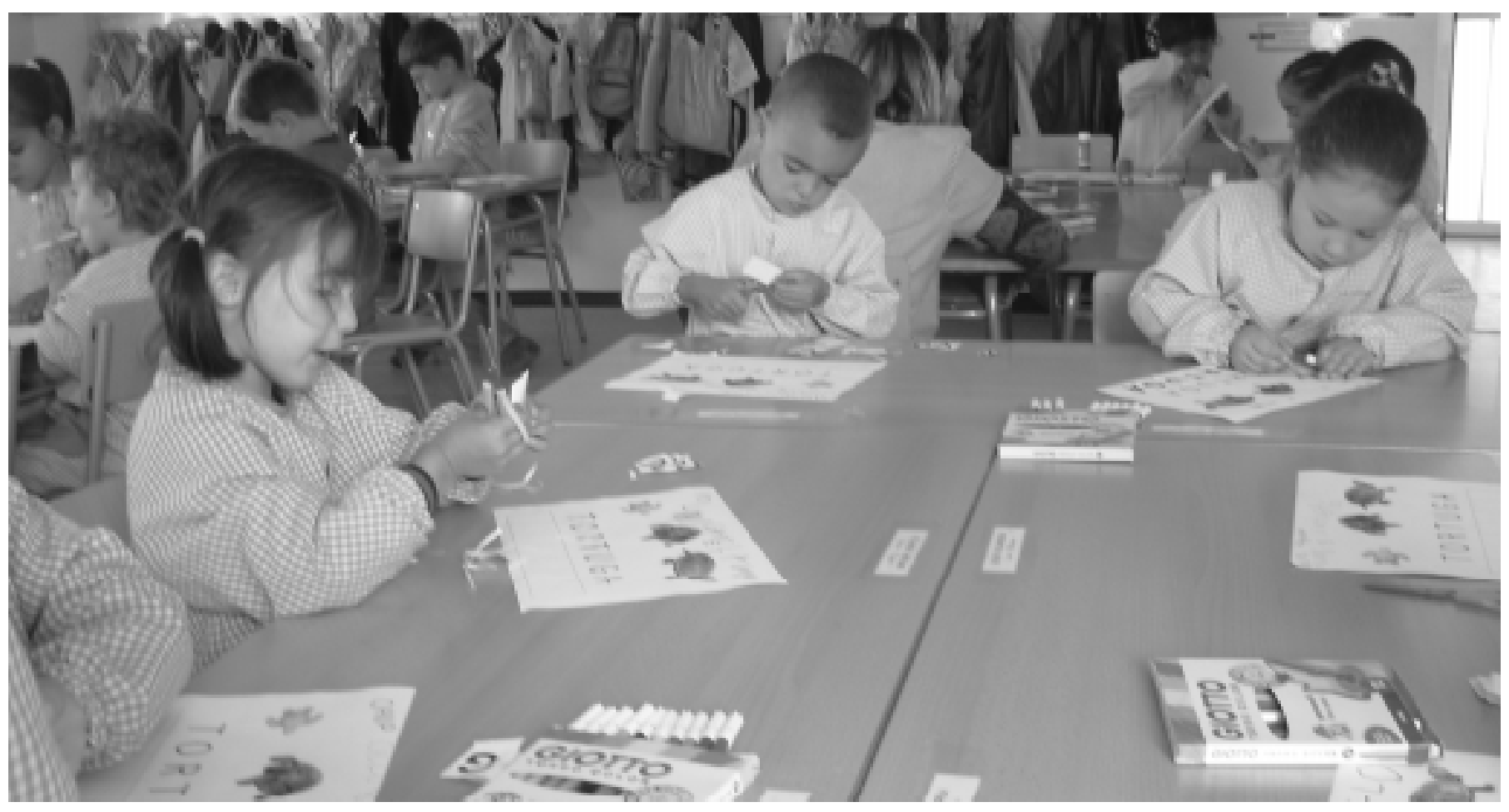

